\title{
GAMBARAN KEMAMPUAN INTERAKSI SOSIAL PASIEN ISOLASI SOSIAL SETELAH PEMBERIAN SOCIAL SKILLS THERAPY DI RUMAH SAKIT JIWA
}

\author{
Sukma Ayu Candra Kirana \\ Prodi S1 Keperawatan \\ STIKES Hang Tuah Surabaya \\ email : sukmaayucandrakirana@stikeshangtuah-sby.ac.id
}

\begin{abstract}
Social isolation is one of the nursing diagnoses that can be established in patients who are symptomatic to withdraw, withdraw from social activities and do not want to interact with others even with nurses. Negative symptoms such as social isolation that can not be overcome can cause the client to experience positive symptoms and worsen her condition. One way to improve the interaction of patients with social isolation is to use Social Skills Therapy. The purpose of this research is to know the description of change of interaction ability of social isolation patient after given Social Skills Therapy. The method used was descriptive with 40 respondents of social isolation who were treated in one of the RSJ inpatient rooms in West Java, Indonesia. The result of this research is an increase of social interaction ability after given Social Skills Therapy. Therefore Social Skills Therapy can be recommended as one of the specialist therapies in providing nursing care in patients with social isolation.

Keywords : Social isolation client, Social Skills Training, interaction ability.
\end{abstract}

\begin{abstract}
Abstrak: Isolasi sosial adalah salah satu diagnosa keperawatan yang dapat ditegakkan pada pasien yang menunjukkan gejala menyediri, menarik diri dari kegiatan sosial serta tidak mau berinteraksi dengan orang lain bahkan dengan perawat. Gejala negatif seperti isolasi sosial yang tidak dapat diatasi dapat mengakibatkan klien mengalami gejala positif dan semakin memperburuk kondisinya. Salah satu cara untuk meningkatkan kemampuan interaksi pasien dengan isolasi sosial adalah dengan menggunakan terapi Social Skills Therapy. Tujuan dari penelitian ini adalah mengetahui gambaran perubahan kemampuan interaksi pasien isolasi sosial setelah diberikan terapi Social Skills Therapy. Metode yang digunakan adalah deskriptif dengan 40 responden isolasi sosial yang dirawat disalah satu ruang rawat inap RSJ di Jawa Barat, Indonesia. Hasil dari penelitian ini adalah terjadi peningkatan kemampuan interaksi sosial setelah diberikan Social Skills Therapy. Oleh sebab itu Social Skills Therapy dapat direkomendasikan sebagai salah satu terapi spesialis dalam memberikan asuhan keperawatan pada pasien dengan isolasi sosial.
\end{abstract}

Kata kunci : isolasi sosial, social skills therapy, kemampuan interaksi sosial.

\section{PENDAHULUAN}

Gangguan jiwa adalah pola psikologis yang diperlihatkan oleh individu berupa distress, gangguan fungsi dan penurunan kualitas hidup Stuart (2013). RISKESDAS tahun 2013 menunjukan data gangguan jiwa berat sebesar $0,17 \%$, atau sekitar 1,1 juta orang atau 5,2\% dari jumlah penderita Skizofrenia di seluruh dunia. Skizofrenia adalah gangguan jiwa yang dapat ditunjukkan dengan penurunan dan ketidakmampuan berkomunikasi, gangguan realita (halusinasi dan waham), afek tumpul atau tidak wajar,gangguan kognitif (ketidakmampuan berfikir abstrak) serta kesulitan melakukan aktivitas sehari-hari (Kirana, SAC, Keliat, BA, Mustikasari, 2015)

Gejala skizofrenia dapat digolongkan menjadi 2 gejala yaitu gejala positif dan gejala negatif (Videback, 2014).Sebagian besar dari gejala negatif 
pasien dengan skizofrenia dapat berupa isolasi sosial.

Isolasi sosial merupakan kondisi dimana pasien selalu merasa sendiri dengan merasa kehadiran orang lain sebagai ancaman (Fortinash, 2011). Penurunan produktifitas pada pasien menjadi dampak dari isolasi sosial yang tidak dapat ditangani (Brelannd-Noble $e t$ al, 2016). Oleh sebab itu tindakan keperawatan yang tepat sangat dibutuhkan agar dampak yang ditimbulkan tidak berlarut larut.

Gejala yang muncul pada klien isolasi sosial meliputi gejala kognitif antara lain, perasaan kesepian, merasa ditolak orang lain atau lingkungan, merasa tidak dimengerti oleh orang lain, merasa tidak berguna, putus asa, tidak memiliki tujuan hidup, merasa tidak aman berada diantara orang lain, menghindar, tidak mampu konsentrasi dan membuat keputusan (Fortinash, 1999; Keliat, 2010); Townsend, 2009; NANDA, 2012). Gejala afektif yang muncul adalah lebih banyak memiliki gejala negatif seperti sedih,tertekan, depresi, marah, kesepian, ditolak orang lain, apatis, malu. (Stuart \& Laraia, 2005). Perilaku yang sering ditunjukkan oleh klien isolasi sosiail lebih banyak menarik diri, menjauh dari orang lain, jarang berkomunikasi, tidak ada kontak mata, malas, tidak beraktifitas, menolak hubungan dengan orang lain (Townsend, 2009).

Stuart, (2013) menjelaskan bahwa dampak dari perilaku klien isolasi sosial sering tidak dijadikan prioritas karena tidak mengganggu secara nyata. Namun apabila isolasi sosial tidak ditangani, maka akibat yang ditimbulkan dapat berupa risiko perubahan sensori persepsi : halusinasi sebagai bentuk gejala negatif yang tidak tertangani dan dapat memicu terjadinya gejala positif (Stuart, 2013). Depresi juga dapat terjadi pada klien halusinasi dengar sebesar $40 \%$. Kejadian bunuh diri juga terjadi pada $9 \%$ sampai $13 \%$ klien schizofrenia, percobaan bunuh diri juga dilakukan klien skizofenia sebesar 20-50\%. Berdasarkan akibat tersebut setidaknya perawat memiliki peran penting dalam memberikan intervensi keperawatan baik secara individu atau keluarga.

Tidak lebih dari $10 \%$ klien skizofrenia dapat berfungsi dengan baik dengan pendekatan terapi antipsikotik, sedangkan $90 \%$ sisanya membutuhkan berbagai pendekatan dinamis termasuk farmakoterapi, terapi individu, terapi kelompok, terapi keluarga, dan perawatan rumah sakit (Fausiah dan Widury, 2005). Riset terkait pelaksanaan terapi pada klien isolasi sosial juga telah dilakukan oleh Kirana, SAC, Keliat BA, Mustikasari, (2015), tentang pengaruh Cognitive BehavioralSocial Skills Training (SST) pada klien isolasi sosial juga mendapatan hasil peningkatan kemampuan kognitf dan perilaku pada klien yang mendapatkan terapi SST.

Perkembangan riset lain yang menjelaskan bahwa Cognitive Behavioral Therapy (CBT) dan Social Skills Training (SST) efektif untuk meningkatkan kualitas hidup klien skizofrenia usia muda, namun terapi tersebut tidak ditujukan untuk memenuhi kebutuhan spesifik klien skizofrenia usia pertengahan dan usia lanjut (McQuaid, 2000).

Peneliti ingin mengetahui gambaran penerapkan terapi spesialis yang mampu mengatasi gejala kognitif, afektif dan perilaku yang dialami oleh klien isolasi sosial serta meningkatkan kemampuan interaksi sosial klien. Penelitian ini diharapkan menjadi penelitian rujukan 
yang dapat digunakan sebagai bentuk psikoterapi yang dapat meningkatkan kemamapuan interaksi sosial klien isolasi sosial di Rumah Sakit Jiwa

\section{METODE}

Desain penelitian yang digunakan pada penelitian ini adalah penelitian deskriptif. Metode pengambilan sampel dengan teknik purposive sampling. Penelitian dilakukan untuk memperoleh gambaran perubahan kemampuan interaksi pasien isolasi sosial setelah diberikan terapi Social Skills Therapy. Data yang didapatkan dari penelitian ini terdiri dari data demografi responden untuk mendapatkan karakteristik responden yang meliputi usia, pendidikan, pekerjaan, status perkawinan, lama rawat, serta data kemampuan interaksi sosial melalui observasi hasil tiap sesi terapi SST. Pengambilan data demografi menggunakan lembar kuesioner data demografi yang terdiri dari 7 pertanyaan dengan cara checklist dan mengisi kolom jawaban yang tersedia. Pelaksanaan terapi SST terdiri dari 4 sesi.

Proses pelaksanaan ini dilakukan dalam kurun waktu setiap 2 hari sekali secara berselingan sesuai jadwal yang sudah disepakati dengan responden. Penelitian ini dilakukan pada bulan Agustus 2016 selama 3 bulan berturut turut. Analisis data menggunakan komputer, analisis univariat digunakan untuk menganalisis variabel - variabel yang ada secara deskriptif dengan menghitung distribusi frekuensinya untuk data katagorik dan tendensi sentral untuk data numerik. Namun tidak diperlukan uji statistik karena penelitian hanya deskriptif saja.

\section{HASIL DAN PEMBAHASAN}

Karakteristik klien isolasi sosial dalam penelitian ini berdasarkan usia memiliki rerata usia 36 tahun dengan usia terendah 19 tahun dan usia tertinggi yaitu 58 tahun. 34 klien atau sebesar $85 \%$ berpendidikan rendah. 38 klien atau $95 \%$ tidak bekerja. Klien yang belum menikah 35 klien atau sebesar 87,5\% sedangkan klien yang berstatus perkawinan menikah adalah 5 klien atau sebesar 12,5\%. Lama dirawat lebih banyak pada 1-2bulan yaitu sebanyak 38 klien atau sebesar 95\%.

Faktor predisposisi terjadinya isolasi sosial telah diidentifikasi berdasarkan tiga aspek yaitu biologi, psikologis dan sosial budaya. Faktor biologis terbanyak didapatkan data riwayat gangguan jiwa sebelumnya sebanyak 31 klien atau sebesar 77,5 \%. Faktor psikologis terbanyak adalah riwayat introvert sebanyak 35 klien atau sebesar 87,5\% sedangkan faktor sosial budaya terbanyak adalah masalah ekonomi keluarga dan klien pribadi sebanyak 31 klien atau sebesar 77,5\%.

Faktor biologis klien isolasi sosial terbanyak adalah riwayat putus obat atau pengobatan yang tidak rutin yakni sebanyak 35 klien atau sebesar 95\%. Faktor psikologis terbanyak riwayat keinginan yang tidak terpenuhi (harapan yang tidak realistis) sebanyak 32 klien atau sebesar $80 \%$. Sedangkan faktor sosial budaya terbanyak adalah tidak adanya penghasilan atau kondisi ekonomi yang kurang sebanyak 31 klien atau sebesar 77,5\%. Asal stresor yang dialami klien isolasi sosial dalampenelitian ini menunjukkan bahwa seluruh klien memperoleh stresor baik dari faktor internal maupun eksternal dari luar klien sebesar 100\%. Waktu stresor yang dialami klien sebagian besar adalah 3-6 bulan sebanyak 33 klien atau sebesar $82,5 \%$ dan jumlah stresor yang dialami sebagian besar klien isolasi 
sosial lebih dari 3 stresor yakni sebanyak 30 klien atau sebesar $75 \%$.

Klien isolasi sosial mengalami respon terhadap stresor baik secara kognitif, afektif, fisiologis, perilaku maupun sosial. Respon tersebut muncul karena klien memahami dan berpengaruh terhadap situasi yang dialaminya. Respon yang paling banyak dialami oleh klien isolasi sosial dalam penelitian ini adalah respon perilaku yaitu kontak mata yang kurang atau tidak adanya kontak mata.

Kemampuan personal klien dengan isolasi sosial lebih banyak mampu berkenalan dengan orang lain yaitu sebanyak 29 klien atau sebesar 72,5\% namun klien isolasi sosial lebih banyak tidak mampu mengungkapkan siapa orang terdekatnya, siapa orang yang tinggal serumah dan pengalaman dalam interaksi bersama orang lain. Dukungan keluarga sebagai care giver utama hanya didapatkan pada 20 keluarga dari klien, 18 keluarga tidak mengetahui penyakit yang dialami keluarganya atau sebesar $90 \%$.

Ketersediaan materi lebih banyak ditunjang oleh penghasilan keluarga yaitu sebanyak 37 klien atau sebesar 92,5\%. Jarak dalam menggunakan pelayanan kesehatan baik ke Puskesmas maupun rumah sakit mudah dijangkau sebanyak 31 klien atau sebesar 77,5\%. Pelayanan kesehatan yang dipiilih oleh klien dan keluarga adalah RS. Dr. Marzoeki Mahdi Bogor sebanyak 35 klien atau sebesar 87,5\%. Pembiayaan selama perawatan di rumah sakit ditanggung oleh pemerintah melalui program jaminan kesehatan masyarakat dan daerah sebanyak 36 klien atau 90\%. Keyakinan positif bahwa diriya akan sembuh dimiliki sebanyak 31 klien atau $77,5 \%$, klien juga yakin dengan perawatan dan pengobatan yang diberikan yaitu sebanyak 36 klien atau $90 \%$.

\begin{tabular}{|c|c|c|c|c|c|}
\hline \multirow{2}{*}{$\mathrm{N}_{0}$} & \multirow{2}{*}{$\begin{array}{l}\text { Standar Tindakan Spesialis Social } \\
\text { Skitls Iraimining(SST) } \\
\end{array}$} & \multicolumn{4}{|c|}{ Jumlah dan Presentase } \\
\hline & & & & & \\
\hline 1 & Lathan Bersosialisasi dengan sikan tibuhl & $\frac{104 \text { ants }}{40}$ & $\frac{\%}{100}$ & $\frac{\text { Delliw }}{8}$ & $\frac{\pi}{n}$ \\
\hline & yg baik dan menja awab pestanyaan & & & & \\
\hline 2. & Latilhan menjalin persadabatan & 40 & 100 & 0 & 0 \\
\hline 3. & Latihan bekerjasama dalam kelompok & 28 & 75 & 2 & 25 \\
\hline 4. & Latihan mengatasi situasi yang sulit & 21 & 52,5 & 19 & 47,5 \\
\hline
\end{tabular}

Tabel4.13 menjelaskan bahwa pelaksanaan terapi SST tidak dapat tuntas dalam 4 sesi. Sesi 1: bersosialisasi dengan berkenalan dengan sikap tubuh yang baik, menjawab pertanyaan dan bertanya untuk klarifikasi, dan sesi 2 : menjalin persahabatan tuntas dilakukan pada 40 pasien. Sesi 3 : bekerja sama dalam kelompok hanya dapat dilakukan pada 28 pasien. Sedangkan yang tuntas sampai sesi terakhir yakni sesi 4 : menghadapi situasi yang sulit hanya 21 pasien.

Hal tersebut disebabkan oleh masa rawat klien yang dibatasihanya 41 hari dimulai dari ruang perawatan pertama. Sedangkan klien masuk ke Ruang tenang tersebut rata rata memiliki hari rawat ke 15-20 hari. Hal tersebut menjadi hambatan dalam pelaksanaan terapi SST yang tidak bisa diselesaikan sampai selesai $(67,5 \%)$. Oleh sebab itu peneliti menyarankan untuk memulai SST pada klien yang sudah mendapatkan tindakan generalis dan memiliki kemampuan sosialisasi sebelumnya dalam tingkat generalis.

\section{Tabel 6 Distribusi Evaluasi Kemampuan Klien Isolasi Sosial Setelah Mendapatkan Terap Spesialis (SST) (n=40)}

\begin{tabular}{|c|c|c|c|c|c|c|}
\hline \multirow{2}{*}{ Kemampuan } & \multicolumn{2}{|c|}{ Pre } & \multicolumn{2}{|c|}{ Post } & \multicolumn{2}{|c|}{ Selisih } \\
\hline & $\mathrm{Jml}$ & $\%$ & $\mathrm{Jml}$ & $\%$ & $\mathrm{Jml}$ & $\%$ \\
\hline Spesialis pada klien ( $\mathrm{n}=40$ ) & & & & & & \\
\hline 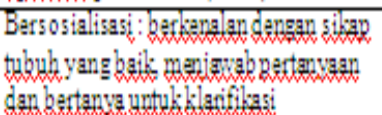 & 9 & 22,5 & 27 & 67,5 & 18 & 45 \\
\hline $\begin{array}{l}\text { Menjalin persahabatan : memirta dan } \\
\text { mambaribanpertolongan maminta dan } \\
\text { mambarikanpujian }\end{array}$ & 4 & 10 & 32 & 80 & 28 & 70 \\
\hline Bakerja sama dalam kalompok & 2 & 5 & 28 & 70 & 26 & 65 \\
\hline
\end{tabular}


Pada tabel 6 distribusi evaluasi kemampuan klien dalam terapi SST tidak diukur berdasarkan jumlah responden. Namun berdasarkan jumlah responden yang mampu menunjukkan peningkatan kemampuan tiap sesi dari SST tersebut. Nilai selisih yang ditampilkan adalah nilai selisih pasien yang mampu melalui tahap tiap sesi sesudah diberikan terapi SST dikurangi jumlah pasien yang mampu melalui tahap sesi 1 sebelum pemberian terapi SST. Oleh sebab itu jumlah tidak dapat ditotal menjadi 40, hal tersebut menandakan bahwa tidak seluruhnya pasien isolasi sosial dapat mengalami peningkatan kemampuan interaksi sosialnya melalui pelaksanaan tiap sesi.

Klien yang tidak mengalami peningkatan kemampuan interaksi sosial dapat dirujuk ke tim medis dengan meninjau terapi medis yang diberikan dan juga penetapan diagnose medis berdasarkan respons yang masih dimilki oleh klien. Sehingga dapat dirumuskan psikoterapi yang cocok sebagai latihan ketrampilan selanjutnya yang akan dipimpin oleh perawat, khususnya perawat spesialis jiwa di ruangan tersebut atau perawat lain yang berkompeten, seperti supervisor yang bertanggung jawab di ruangan tersebut.

Peningkatan kemampuan interaksi sosial pada pasien isolasi sosial dapat terjadi akibat hubungan atau interaksi yang baik antara perawat dengan klien. Sebelum terapi SST diberikan klien mendapatkan terapi generalis terlebih dahulu baik secara individu maupun kelompok. Melalui kerjasama dengan perawat ruangan dan mahasiswa yang praktek di ruang tenang psikiatri di salah satu Rumah Sakit Jawa Barat. Penulis melakukan terapi SST pada 40 klien isolasi sosial dengan syarat telah mendapatkan terapi generalis individu pada SP 2 dan terapi kelompok TAKS padasesi1-2. Hal tersebut diantisipasi penulis agar klien tidak mengalami SST yang tidak tuntas.

Kemampuan klien dalam berinteraksi sosial tidak terlepas dari proses belajar. Dalam pelaksanaan SST klien diberi informasi dan cara belajar ketrampilan baru dalam bersosialisasi(Callafel et al, 2014). Melalui pendekatan interpersonal relationship, tindakan keperawatan dapat dengan mudah diaplikasikan pada tiap sesi pelaksanaan terapi SST. Klien isolasi social membutuhkan hubungan antara perawat dan klien yang lebih dalam dan memiliki lingkungan yang terapeutik (Williams B, 2015).

Kemampuan interaksi sosial klien isolasi sosial dapat terlihat dengan berkurangnya kesendirian klien, kontak mata klien pada orang lain serta kemajuan klien dalam berinterksi dengan orang lain. Berdasarkan hasil pelaksanaan tindakan keperawatan spesialis didapatkan data bahwa terjadi penurunan tanda dan gejala baik kognitif, afektif, fisiologis, perilaku dan sosial klien melalui SST. Hal ini juga tergambar dalam penelitian Kirana SAC, Keliat BA, Mustikasari, (2015) yang mengalami penurunan tanda dan gejala isolasi sosial serta peningkatan interaksi klien saat pelaksanaan SST dalam terapi CBSST. 
Berdasarkan evaluasi terhadap tindakan keperawatan SST pada klien dengan isolasi sosial ditemukan beberapa hambatan antara lain tidak semua klien mengikuti secara tuntas pelaksanaan SST hal tersebut disebabkan ada beberapa klien yang sudah diperbolehkan pulang dan dijemput keluarga untuk melanjutkan pengobatan dipoliklinik.

\section{KESIMPULAN}

Karakteristik klien isolasi sosial dalam penelitian ini berdasarkan usia memiliki rerata usia 36 tahun, 34 klien berpendidikan rendah,38 klien tidak bekerja. Klien yang belum menikah 35 klien. Lama dirawat lebih banyak pada 1-2 bulan yaitu sebanyak 38 klien atau sebesar $95 \%$.

Pelaksanaan SST pada 40 klien tidak dapat tuntas akibat lama rawat pasien yang tidak dapat memanjang akibat peraturan pemerintah yang hanya merawat pasien 41 hari dengan menggunakan fasilitas jaminan kesehatan pemerintah. Sedangkan pasien pindah ke ruangan tenang minimal pada hari rawat 15-20 hari. Sehingga dibutuhkan tindakan keperawatan yang konsisten dan teroganisir sesuai kondisi pasien agar tindakan keperawatan baik generalis maupun spesialis dapat dilaksanakan dengan tuntas tanpa kendala waktu rawat pasien.

Terdapat perubahan kemampuan interaksi sosial pasien isolasi sosial sebelum dan sesudah pemberian Social Skills Therapy di tiap pelaksanaan sesinya. Sehingga psikoterapi ini dapat direkomendasikan sebagai tindakan keperawatan dalam meningkatankan kemampuan interaksi sosial pasien dengan isolasi sosial.

\section{DAFTAR PUSTAKA}

Breland-Noble A.M et all, (2016). Handbook of mental health in african american Youth. Springer, London:New York

Calafell, et al (2014).Social skills training for people with schizophrenia: what do we train?.Behavioral Psychology / Psicología Conductual, Vol. 22, No 3, 2014, pp. 461-477

Departemen Kesehatan Republik Indonesia. (2013). Riset kesehatan dasar 2013.

http://www.litbang.depkes.go.id/

LaporanRKD/IndonesiaNasional. pdf. diakses tanggal 22, Mei 2015

Fausiah, F., dan Widury, J. (2005). Psikologi Abnormal Klinis Dewasa. Jakarta : UIPress.

Fortinash \& Worret. (2011). Psychiatric Mental Health Nursing. ( $5^{\text {rd }}$ ed.). St. Louis: Mosby

Keliat, B.A. dkk. (2010). Management Praktek Keperawatan Profesional, EGC Jakarta

Kirana, Keliat \& Mustikasari. (2015). Pengaruh Cognitive Behaviour Therapy dan Cognitive Beharioral Social Skills Training Terhadap Gejala Klien Halusinasi dan Isolasi Sosial. Jurnal Keperawatan Stikes Hang Tuah Surabaya Edisi Maret 2016

McQuaid, dkk. (2000). Development of an Integrated CognitiveBehavioral andSocial Skills training Intervention for Older Patients With Schizophrenia. The Journal of Psychotherapy Practice and Research, 9(3), 149-156

NANDA. (2012). Nursing Diagnosis, NANDA International, Canada. 
Stuart, G.W. (2013). Principles and Practice of Psychiatric Nursing. $10^{\text {th }}$ Ed. Canada: Evolve.]

Stuart, G.W. \& Laraia, M.T. (2005). Principles and Practice of Psychiatric Nursing, 8th ed. Missouri : Mosby, Inc.

Townsend, M.C. (2009). Psychiatric Mental Health Nursing, Concepts of Care in Evidence-Based Practice. $6^{\text {th }}$ Ed. Philadelphia: Davis Plus.

Videback, S.L. (2014). PsychiatricMental Health Nursing. $6^{\text {th }}$ Ed. China: Wolters Kluwer.

WHO. (2009). Investing in Mental Health. Switzerland : Nove Impression. 